\title{
Blockade of endogenous growth hormone-releasing hormone receptors dissociates nocturnal growth hormone secretion and slow-wave sleep
}

\author{
Stacy K Jessup ${ }^{1}$, Beth A Malow ${ }^{2}$, Kathleen V Symons ${ }^{3}$ and Ariel L Barkan ${ }^{1,3}$ \\ ${ }^{1}$ Department of Internal Medicine, Division of Endocrinology and Metabolism, University of Michigan Medical Center, ${ }^{2}$ Department of Neurology, \\ University of Michigan Medical Center, Ann Arbor, Michigan, USA and ${ }^{3}$ Department of Veterans Affairs Medical Center, Ann Arbor, \\ Michigan 48105, USA \\ (Correspondence should be addressed to A Barkan; Email: abarkan@umich.edu)
}

\begin{abstract}
Objectives: A temporal association between non-rapid eye movement (NREM) sleep stages 3 and 4 and nocturnal augmentation of $\mathrm{GH}$ release was found long ago, yet the precise mechanism for this association has not been identified. It has been shown, however that pulsatile GHRH administration increases both slow-wave sleep (SWS) and GH. Based on these data, a role for GHRH as an inducer of SWS was proposed. To test this hypothesis, we have performed the corollary experiment whereby the action of endogenous GHRH has been antagonized.

Design: Healthy men (20-33 years old) had an infusion of GHRH antagonist ( $\left(\mathrm{N}-\mathrm{Ac}-\mathrm{Tyr}^{\mathrm{C}}{ }^{\mathrm{D}} \mathrm{D}-\mathrm{Arg}^{2}\right)$ GHRH-29 $\left(\mathrm{NH}_{2}\right)$ ) or saline for a 12-h period, between 2100 and $0900 \mathrm{~h}$. An i.v. bolus of GHRH was given at $0700 \mathrm{~h}$ and $\mathrm{GH}$ samples were drawn from 0700 to $0900 \mathrm{~h}$ to document the efficacy of GH suppression by the GHRH antagonist.

Methods: A limited montage sleep study was recorded from 2300 to $0700 \mathrm{~h}$ during each admission. Plasma GH concentrations were analyzed by the use of a sensitive chemiluminometric assay.

Results: Effectiveness of the GHRH antagonist was validated in all subjects by demonstrating $93 \pm 1.8 \%(P=0.012)$ suppression of GH response to a GHRH bolus. Polysomnography demonstrated that the percentage of SWS was not different when saline and GHRH antagonist nights were compared $(P=0.607)$; other quantifiable sleep parameters were also unchanged.

Conclusions: We conclude that endogenous GHRH is indispensable for the nocturnal augmentation of GH secretion, but that it is unlikely to participate in the genesis of SWS.
\end{abstract}

European Journal of Endocrinology 151 561-566

\section{Introduction}

Sleep architecture is organized into rapid eye movement (REM) sleep and four stages of non-REM (NREM) sleep based on polysomnography. Based on the temporal association between the nocturnal rise of growth hormone (GH) and NREM stages 3 and 4 slow-wave sleep (SWS), a search for a common denominator was initiated. In a study that measured GH every $30 \mathrm{~s}$ during sleep, it was found that maximal $\mathrm{GH}$ release occurs after a 4.5-min time delay from the onset of SWS (1). In men, $70 \%$ of $\mathrm{GH}$ pulses occur together with SWS (2). Administration of gamma-hydroxybutyrate to humans augmented both SWS and nocturnal $\mathrm{GH}$ release (3). The interrelationships between the somatotropic axis and sleep architecture remain to be elucidated. The associations between SWS and GH release may be correlative, or even causative. One possibility is that the mechanisms leading to the events of
SWS promote GH release. This is supported by the time course of the two phenomena, whereby SWS actually precedes the GH release (1). A reverse possibility, whereby the hormonal components of the nocturnal GH peak participate (or even cause) in the genesis of SWS is also theoretically possible. Based on the latter possibility, a search into potential roles of different hormonal components of the nocturnal GH surge as the inducers of SWS has been launched. When exogenous GH was given to humans, SWS was unaffected or actually decreased $(4,5)$. Somatostatin also did not affect sleep architecture when given to young healthy men (6). A synthetic ghrelin agonist, GHRP-2 given as discrete boluses did not affect SWS (7). Another ghrelin agonist, GHRP-6, actually prolonged stage 2 of sleep (8), but SWS was not affected.

The nocturnal GH pulse is thought to be secondary to growth hormone-releasing hormone (GHRH) release, and it has been shown that GHRH antagonist 
blocks this pulse in humans (9). Thus, the effect of endogenous GHRH on sleep architecture was naturally postulated.

The effects of GHRH on sleep architecture have been studied more directly in the rat model. The somnogenic effect of exogenous GHRH was not blocked in hypophysectomized rats, suggesting that this effect was $\mathrm{GH}$ independent (10). Administration of specific antiGHRH serum disrupted sleep, suggesting that endogenous GHRH contributed to sleep regulation. (11). In addition, intrapreoptic injection of GHRH antagonist decreased the intensity of NREM sleep (12). Whether endogenous GHRH affects sleep architecture in humans is uncertain. When given episodically, GHRH was found to enhance SWS $(13,14)$. The efficiency of GHRH in promoting sleep decreases in the elderly, in depression and during the second half of the night (15). Conversely, the ability of GHRH to provoke a secretory GH response is dependent upon the stage of sleep, and awakening inhibits the secretory response of GHRH (16). These data have suggested that the hierarchy of the sleep/GH relations may be in fact opposite to the older model, i.e. it is the GHRH that may cause the SWS and not vice versa.

This protocol investigated the physiological relevance of endogenous GHRH to sleep architecture using a competitive GHRH antagonist in healthy men.

\section{Materials and methods}

\section{Human subjects}

The institutional review board of the University of Michigan Medical School approved this study. Each subject signed an informed consent document before enrolling and participating in the protocol.

Eleven young (age range 20-33 years, average age $23.5 \pm 2.1$ years) men were recruited from the community. All were found to be healthy based on medical history, physical examination and routine hematological and biochemical testing. Specifically, their testosterone $(4.1 \pm 0.76 \mathrm{ng} / \mathrm{ml})$ and insulin-like growth factor-I (IGF-I; $288 \pm 40 \mu \mathrm{g} / \mathrm{l}$ ) values were within normal limits. None of the subjects were taking any medications; subjects denied use of over-the-counter sleep aids. None of the subjects had a history of recent transmeridian travel, caffeine dependence or night shift work. All subjects were non-obese (body mass index $23.7 \pm 0.43 \mathrm{~kg} / \mathrm{m}^{2}$ ), non-drinkers and non-smokers.

\section{Protocol}

The study was performed at the General Clinical Research Center (GCRC) of the University of Michigan. Subjects were admitted and studied twice. In random order, the subjects received either a continuous 12-h infusion of GHRH antagonist (N-Ac-Tyr ${ }^{1}$, D-Arg ${ }^{2}$ ) GHRH(1-29) (Bachem, King of Prussia, PA, USA) at
$33 \mu \mathrm{g} / \mathrm{kg}$ per hour or an infusion of normal saline at the same rate $(15 \mathrm{ml} / \mathrm{h})$. The studies were performed with at least 1 week between admissions. Meal times were standardized and caffeine and napping were prohibited. Data from studies investigating the effect of GHRH upon SWS $(13,17)$ were used to perform power analysis. Assuming that the magnitude of the supposed decline in the percentage of SWS during GHRH antagonist infusion would be similar to the reported increase in SWS during GHRH administration, we would need $4-12$ subjects per group to have an $80 \%$ power to document this effect at 5\% statistical level.

Subjects were admitted at $1800 \mathrm{~h}$ on day 1 . The first night of the study was used for acclimatization purposes. An i.v. line was taped to the subject's forearm to simulate an i.v. drip so that patients would be accustomed to the sensation overnight. The sleep technician placed electrodes for a limited montage electroencephalogram (EEG) (four EEG channels, one chin electromyogram and two electro-olfactogram channels for polysomnographical recording). Lights were turned off at $2300 \mathrm{~h}$ and turned on at $0700 \mathrm{~h}$. On day 2 subjects were allowed a pass from the GCRC to avoid poor sleep hygiene, as it was counter-productive for them to remain in a hospital bed all day. Subjects were reminded to avoid caffeine and napping. Upon the subject's return at $1800 \mathrm{~h}$, two heparinized cannulas were inserted into veins in both forearms for the purpose of blood drawing and the infusion. The sleep technician placed EEG electrodes again and recording began at $2300 \mathrm{~h}$ (lights out) and continued until awakening. On day 2, at $2100 \mathrm{~h}$ an infusion of GHRH antagonist or saline was begun and continued until $0900 \mathrm{~h}$ on day 3. A bolus of GHRH-44 (0.33 $\mu \mathrm{g} / \mathrm{kg}$; Bachem, Torrance, CA, USA) was given on day 3 at $0700 \mathrm{~h}$. As we have shown previously, this dose causes acute $\mathrm{GH}$ release of a magnitude approximating the nocturnal GH surge (17) and, thus, can be viewed as physiological. Originally, we intended to study the effects of GHRH antagonist on sleep architecture and $\mathrm{GH}$ secretion in the same group of subjects. Unfortunately, pilot studies in the first six subjects have shown that the procedure of frequent blood draws produced frequent awakenings and disruption of sleep architecture as evidenced by the sleep efficiency of below $70 \%$ $(66.8 \pm 3.2 \%)$ in five of the six subjects. Thus, we used only the GH data in these subjects (control group). In the next five subjects, i.v. cannulae were inserted, and either saline or GHRH antagonist were infused in a manner identical to the control group but nocturnal GH sampling was not done, to allow for an undisturbed sleep. However, subjects also underwent GHRH testing in the morning as specified above, with blood draws every $10 \mathrm{~min}$ between 0700 and $0900 \mathrm{~h}$. In this group of subjects, polysomnographic studies were used for the final analysis. Data from the only subject in the original (control) group whose sleep efficiency was $85 \%$ were included in both $\mathrm{GH}$ and sleep analyses. 
A sleep technologist who was blinded to the experimental condition scored the polysomnographic recordings visually using standard criteria (18). NREM sleep stages 1-4, REM sleep and wakefulness were scored at 30-s intervals. Sleep latency with reference to $2300 \mathrm{~h}$, sleep efficiency and REM latency were also determined. Split night reports were generated based on dividing the time between sleep onset and offset exactly in half with similar parameters compared in the first and second half of the sleep period. This was done because other studies (17) have suggested that GHRH may have differential effects on REM and SWS early or late during sleep.

\section{Assays}

Blood samples were centrifuged and plasma was stored at $-20^{\circ} \mathrm{C}$ until assayed. Plasma GH was measured in duplicate using a chemiluminometric assay (Nichols Institute Diagnostics, San Juan Capistrano, CA, USA) with an assay sensitivity of $0.01 \mu \mathrm{g} / \mathrm{l}$ as described previously (19). Samples from both admissions for a single subject were run in the same assay. Assays for screening (complete blood count, biochemical profile, thyroid-stimulating hormone and testosterone) were performed by the Pathology Laboratories of the University of Michigan Medical Center using routine methodologies.

\section{Calculations}

The GH response to GHRH was calculated using the area under the curve of $\mathrm{GH}$ vs time between 0700 and $0900 \mathrm{~h}$. GH output suppression, as well as changes in percentages of the night spent in different sleep stages during the GHRH antagonist infusion, were calculated as a percentage of the corresponding measurements during the saline infusion. Data that were not normally distributed were log transformed before the analysis. Data are shown as means \pm s.e.M. All comparisons between GHRH antagonist and saline protocols were made using two-tailed paired $t$-tests. A $P$ value of $<0.05$ was assumed to indicate statistical significance.

\section{Results}

GHRH antagonist was well tolerated in all subjects. Subjects were blinded to the infusion and could not distinguish between the GHRH antagonist and saline when questioned on day 3. In the absence of nocturnal blood sampling, sleep efficiency was above $80 \%$ $(87.7 \pm 1.4 \%)$ in all six subjects who underwent polysomnographic recording.

In the first six individuals, frequent nocturnal blood sampling disclosed pulsatile GH secretion during saline infusion and its significant blunting during GHRH antagonist infusion. Actual GH profiles in two of these subjects are shown in Fig. 1. GHRH antagonist suppressed mean plasma GH $(2300-0700 \mathrm{~h})$ from $2.46 \pm 0.63$ to $0.51 \pm 0.13 \mu \mathrm{g} / \mathrm{l}$ or by $77 \pm 4.3 \%$ $(P<0.001)$. Similarly, in the same group area under the curve (AUC) of plasma GH after an i.v. GHRH $(0.33 \mu \mathrm{g} / \mathrm{kg})$ at $0700 \mathrm{~h}$ was suppressed from $206 \pm 50$ to $13 \pm 5 \mu \mathrm{g} / \mathrm{l}$ or by $90.2 \pm 3.6 \%(P=0.012)$.

In the subjects who had polysomnographic studies done, GHRH antagonist suppressed the GH rise to exogenous GHRH by $93 \pm 1.8 \%(P=0.012)$ (Fig. 2$)$.

Sleep parameters for the GHRH antagonist and saline infusion nights were virtually identical (Table 1). Specifically, SWS was not influenced significantly $(P=0.607)$ during the suppression of endogenous GHRH action.

Split night reports were generated as GH secretion is generally more pronounced in the first half of the night; again, a comparison of sleep parameters did not demonstrate a significant difference between GHRH antagonist and saline infusion nights (Table 2). Using the current data for a retrospective power analysis, we have estimated that more than 100 subjects per group would be needed to have an $80 \%$ power to show any difference in sleep parameters at 5\% statistical level. Specifically, to find any effect of GHRH antagonist on the point of primary interest for this study, i.e. stage 3-4 SWS, a minimum of 530 subjects per group would be required.

\section{Discussion}

The regulation of the somatotropic axis and sleep appears to be closely related both in animals and in humans. Deep NREM sleep is reliably associated with the robust elevation of plasma GH concentrations during early night hours. Whether this association is merely correlative or causative is still uncertain. However, it is not unreasonable to assume that one or more hormonal components participating in the nocturnal GH pulse may have a NREM sleep-promoting activity as well. In support of this hypothesis are the animal data demonstrating sleep-promoting activities of GH, GHRH and ghrelin and sleep-inhibiting activities of somatostatin and IGF-I (reviewed in reference 20). Surprisingly, the same relations were much more difficult to demonstrate in humans. GHRH was ineffective when given during daytime, before sleep onset or as a continuous infusion (21-23). However, pulsatile boluses of GHRH increased REM sleep or SWS depending on the timing of administration $(13,19)$. We attempted to investigate the GHRH/sleep connection using a corollary experiment, i.e. abolition of GHRH action. To this end, we employed continuous administration of a specific competitive GHRH antagonist. This compound was shown to attenuate the magnitude of spontaneous GH secretory discharges (including the nocturnal $\mathrm{GH}$ pulse) as well as $\mathrm{GH}$ responses to a variety of stimuli, including $\operatorname{GHRH}(9,24)$ in a 

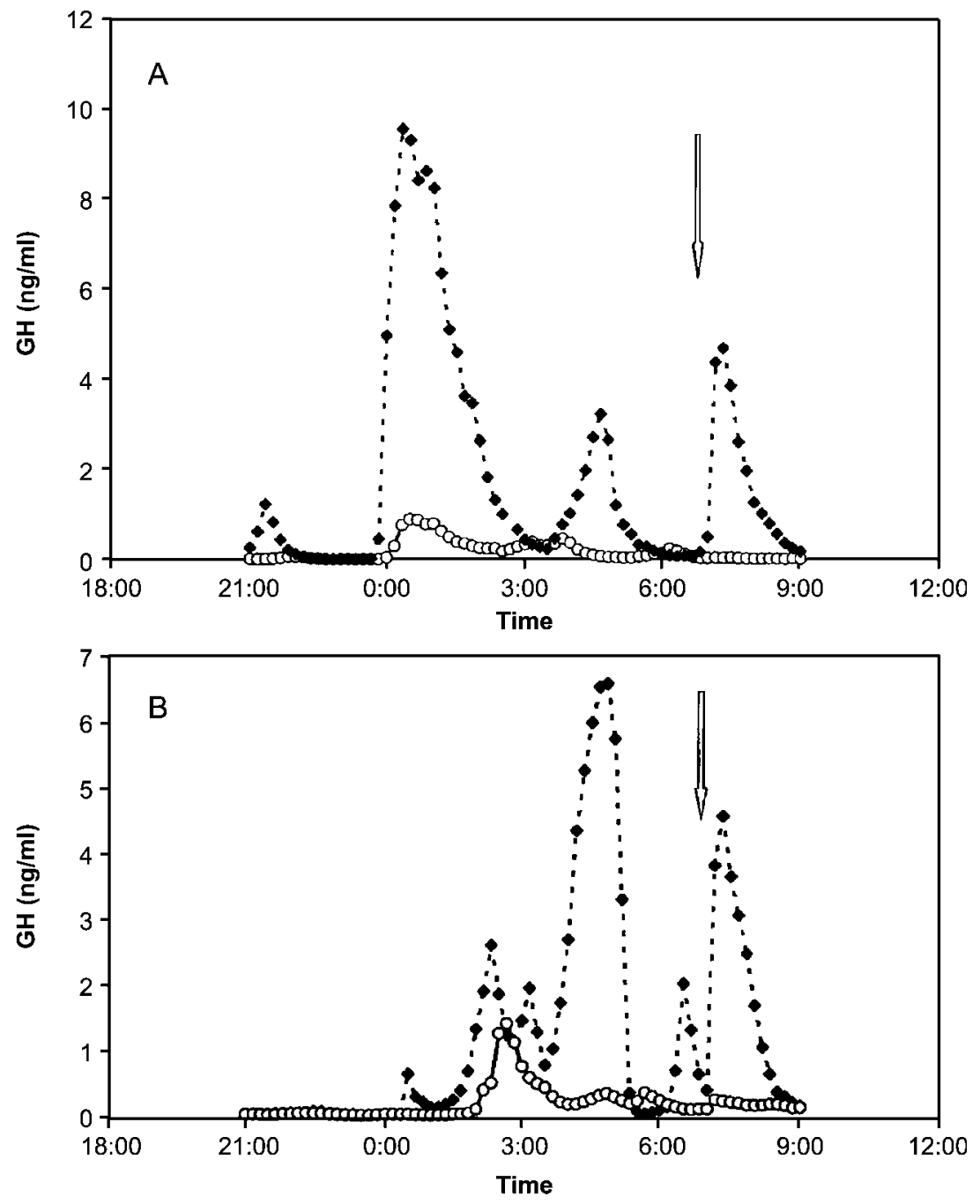

Figure 1 Pulsatile GH profiles of two representative subjects from the control group are shown. Subject B had an average sleep efficiency of $89.8 \%$ during the revised protocol and his sleep data were also included in the final analysis. The i.v. GHRH bolus $(0.33 \mu \mathrm{g} / \mathrm{kg})$ was given at $0700 \mathrm{~h}$ as shown by the arrow. Closed symbols, GH values during normal saline infusion; open symbols, GH values during $\mathrm{GHRH}$ antagonist infusion.

dose-dependent manner. We show here that attenuation of the GHRH effect virtually abolishes the nocturnal GH release but has no effect on sleep architecture. Thus, our study argues against the role of endogenous GHRH as a sleep promoter in humans. It is theoretically conceivable that the limited sample size employed in

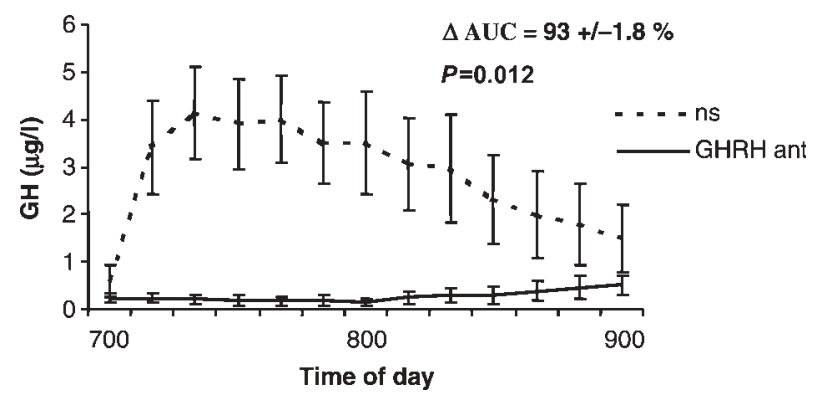

Figure $2 \mathrm{GH}$ responses to i.v. GHRH bolus $(0.33 \mu \mathrm{g} / \mathrm{kg})$ in subjects whose sleep architecture was analyzed. Dashed line, normal saline infusion; continuous line, GHRH antagonist infusion. The i.v. GHRH bolus $(0.33 \mu \mathrm{g} / \mathrm{kg})$ was given at $0700 \mathrm{~h}$. this study prevented the disclosure of more subtle effects of GHRH blockade on SWS. A retrospective power analysis of the data obtained in the course of this study indicate that at least 530 subjects per group would be needed to demonstrate the effect of GHRH blockade on SWS at a 5\% significance level, a number that is not only impractical for a clinical

Table 1 Discrete sleep parameters during normal saline (NS) or $\mathrm{GHRH}$ antagonist (Ant) administration.

\begin{tabular}{lrrl}
\hline Parameter & NS & Ant & $\boldsymbol{P}$ \\
\hline Sleep latency (min) & $24.2 \pm 4.1$ & $16.4 \pm 4.8$ & 0.275 \\
Sleep efficiency (\%) & $85.0 \pm 1.9$ & $90.3 \pm 1.5$ & 0.13 \\
Wake time (min) & $68.6 \pm 8.4$ & $46.8 \pm 7.3$ & 0.162 \\
SWS 1 (\%) & $7.1 \pm 1.4$ & $5.7 \pm 1.0$ & 0.214 \\
SWS 2 (\%) & $50.4 \pm 2.5$ & $52.8 \pm 2.8$ & 0.316 \\
SWS 3 and 4 (\%) & $23.9 \pm 2.6$ & $22.8 \pm 1.8$ & 0.607 \\
REM (\%) & $18.6 \pm 1.3$ & $18.7 \pm 2.2$ & 0.953 \\
REM latency (min) & $89.7 \pm 8.1$ & $111.9 \pm 21.1$ & 0.349 \\
\hline
\end{tabular}


Table 2 Discrete sleep parameters during first and second halves of sleep time.

\begin{tabular}{|c|c|c|c|c|c|c|}
\hline \multirow[b]{2}{*}{ Parameter } & \multicolumn{3}{|c|}{ First half } & \multicolumn{3}{|c|}{ Second half } \\
\hline & NS & Ant & $P$ & NS & Ant & $P$ \\
\hline Recorded time (min) & $213.1 \pm 6.2$ & $226.9 \pm 4.2$ & 0.145 & $212.2 \pm 6.2$ & $225.5 \pm 4.1$ & 0.177 \\
\hline Sleep time (min) & $198.5 \pm 6.1$ & $219.2 \pm 5.8$ & 0.078 & $191.7 \pm 8.4$ & $205.8 \pm 7.3$ & 0.368 \\
\hline Sleep efficiency (\%) & $93.2 \pm 1.0$ & $96.5 \pm 0.9$ & 0.081 & $89.4 \pm 2.2$ & $91.2 \pm 2.5$ & 0.711 \\
\hline Wake time (min) & $14.6 \pm 2.4$ & $8.17 \pm 2.0$ & 0.121 & $20.5 \pm 4.8$ & $19.8 \pm 5.6$ & 0.941 \\
\hline SWS $1(\%)$ & $6.1 \pm 0.9$ & $4.4 \pm 1.0$ & 0.116 & $8.3 \pm 2.3$ & $7.3 \pm 1.3$ & 0.635 \\
\hline SWS 2 (\%) & $49.8 \pm 1.2$ & $49.7 \pm 4.0$ & 0.979 & $50.8 \pm 5.1$ & $55.6 \pm 3.5$ & 0.354 \\
\hline SWS 3 and 4 (\%) & $33.2 \pm 3.0$ & $34.3 \pm 2.8$ & 0.636 & $14.2 \pm 3.4$ & $10.2 \pm 1.3$ & 0.201 \\
\hline REM (\%) & $10.9 \pm 1.5$ & $11.6 \pm 2.5$ & 0.791 & $26.8 \pm 2.0$ & $27.0 \pm 2.9$ & 0.925 \\
\hline Latency (min) & $89.7 \pm 8.1$ & $111.9 \pm 21.1$ & 0.349 & NA & NA & NA \\
\hline
\end{tabular}

NA, not applicable; NS, normal saline; Ant, GHRH antagonist.

study but also indicating an infinitesimally low probability of such an event.

We believe that the amount of GHRH antagonist was sufficiently high to assure major blockade of GHRH receptors since in a control group of young men of similar age and body composition, this dose of GHRH antagonist suppressed spontaneous nocturnal GH release by $77 \pm 4.3 \%$, a value virtually identical to our previous data in yet another group of young, healthy men (25). This dose of GHRH antagonist blocked the response to a GHRH bolus of physiological magnitude (i.e. producing acute $\mathrm{GH}$ release similar in magnitude and duration to the spontaneous nocturnal GH pulse) by $90.2 \pm 3.6 \%$, again similar to our earlier data (25). Since in the actual study group this dose of GHRH antagonist suppressed acute GH rise to GHRH in a manner indistinguishable from that seen in the control group, it is likely that their spontaneous nocturnal GH secretion was also suppressed maximally. We have previously shown $(25,26)$ that the relationship between the dose of GHRH antagonist and the percentage suppression of nocturnal GH secretion is log-linear (as expected from a competitive receptor antagonist) and that only minor incremental GH suppression is seen with GHRH antagonist doses between 3.3 and $33 \mu \mathrm{g} / \mathrm{kg}$ per hour. Thus, to achieve an even higher degree of GHRH receptor blockade one would have to employ antagonist doses that are orders of magnitude higher than the one used this study - a financially impractical design with an uncertain degree of side effects. Thus, for all practical purposes, we have achieved as high a degree of GHRH receptor blockade as is possible in clinical studies. We do not have direct proof that the GHRH antagonist given intravenously was actually reaching the central nervous system (CNS) areas involved in sleep regulation. However, the hypothesis of GHRH being a sleep promoter is based on human studies in which GHRH was given intravenously $(13,19)$. If that was indeed the case, intravenous GHRH antagonist was likely to reach the CNS areas accessible for GHRH. Indeed, this compound was shown to affect $\mathrm{GH}$ secretion when given either intravenously or intracerebroventricularly (27).
Our conclusions conflict with the data from previous studies that have shown that episodic GHRH administration influences SWS $(13,19)$ and we have no ready explanation for this discrepancy. The existence of GHRH receptor subtypes with separate roles for $\mathrm{GH}$ and sleep regulation seems unlikely, as the antagonist used in our study was shown to affect sleep architecture in rats when given directly into the preoptic area (12). It is possible that there may be a threshold GHRH effect on sleep regulation. Marshall et al. (28) have shown that it was the magnitude of GHRH elevation rather than the exposure to repeat lower GHRH levels that promoted SWS in humans. If this is the case, an almost $80 \%$ blockade of GHRH action should have been sufficient to influence sleep architecture. In any case, our results do not lend support to the proposed role of GHRH as a sleep regulator in humans. Humans with mutant GHRH receptor $(29,30)$ may prove to be an ideal model to answer this question.

\section{Acknowledgements}

This study was supported by the Endocrine Fellowship Foundation (S K J), a VA Merit Review Award (A L B), K02 NS2099 (B A M) and M01 RR0042 (GCRC). The authors wish to thank the nursing staff of the GCRC, Mr Cory Martin for performing the polysomnography studies and the study participants.

\section{References}

1 Holl RW, Hartman ML, Veldhuis JD, Taylor WM \& Thorner MO. Thirty-second sampling of plasma growth hormone in man: correlation with sleep stages. Journal of Clinical Endocrinology and Metabolism 199172 854-861.

2 Van Cauter E, Plat L \& Copinschi G. Interrelations between sleep and the somatotrophic axis. Sleep 199821 553-566.

3 Van Cauter E, Plat L, Scharf MB, Leproult R, Cespedes S, L'Hermite-Baleriaux M \& Copinschi G. Simultaneous stimulation of slow-wave sleep and growth hormone secretion by gammahydroxybutyrate in normal young men. Journal of Clinical Investigation $1997 \mathbf{1 0 0} 745-753$.

4 Kern W, Halder R, Al-Reda S, Spath-Schwalbe E, Fehm HL \& Born J. Systemic growth hormone does not affect human sleep. 
Journal of Clinical Endocrinology and Metabolism $1993 \mathbf{7 6}$ $1428-1432$.

5 Steiger A, Antonijevic LA, Bohlhalter S, Frieboes RM, Friess E \& Murck H. Effects of hormones on sleep. Hormone Research 1998 49 125-130.

6 Kupfer DJ, Jarrett DB \& Ehlers CL. The effect of SRIF on the EEG sleep of normal men. Psychoneuroendocrinology 199217 37-43.

7 Moreno-Reyes R, Kerkhofs M, L'Hermite-Baleriaux M, Thorner MO, Van Cauter E \& Copinschi G. Evidence against a role for the growth hormone-releasing peptide axis in human slow-wave sleep regulation. American Journal of Physiology 1998 274 E779-E784.

8 Frieboes R-M, Murck H, Maier P, Schier T, Holsboer F \& Steiger A. Growth hormone-releasing peptide- 6 stimulates sleep, growth hormone, ACTH, and cortisol release in normal man. Neuroendocrinology $19956 \mathbf{6 1} 584-589$.

9 Ocampo-Lim B, Guo W, DeMott-Friberg R, Barkan AL \& Jaffe CA. Nocturnal growth hormone $(\mathrm{GH})$ secretion is eliminated by infusion of GH-releasing hormone antagonist. Journal of Clinical Endocrinology $1996 \mathbf{8 1} 4396-4399$.

10 Obal F Jr, Floyd R, Kapas L, Bodosi B \& Krueger JM. Effects of systemic GHRH on sleep in intact and hypophysectomized rats. American Journal of Physiology 1996270 E230-E237.

11 Obal F Jr, Payne L, Opp M, Alfoldi P, Kapas L \& Krueger JM. Growth hormone-releasing hormone antibodies suppress sleep and prevent enhancement of sleep after sleep deprivation. American Journal of Physiology 1992263 R1078-R1085.

12 Zhang J, Obal F Jr, Zheng T, Fang J, Taishi P \& Krueger JM. Intrapreoptic microinjection of GHRH or its antagonist alters sleep in rats. Journal of Neuroscience 199919 2187-2194.

13 Marshall L, Molle M, Boschen G, Steiger A, Fehm HL \& Born J. Greater efficacy of episodic than continuous growth hormonereleasing hormone (GHRH) administration in promoting slowwave sleep (SWS). Journal of Clinical Endocrinology and Metabolism 199681 1009-1013.

14 Steiger A, Guldner J, Hemmeter U, Rothe B, Wiedemann K \& Holsboer F. Effects of growth hormone-releasing hormone and somatostatin on sleep EEG and nocturnal hormone secretion in male controls. Neuroendocrinology 199256 566-573.

15 Steiger A \& Holsboer F. State of the art review: neuropeptides and human sleep. Sleep 199720 1038-1052.

16 Van Cauter E, Caufriez A, Kerkhofs M, Van Onderbergen A, Thorner MO \& Copinschi G. Sleep, awakenings, and insulin-like growth factor-1 modulate the growth hormone (GH) secretory response to GH-releasing hormone. Journal of Clinical Endocrinology and Metabolism 199274 1451-1459.

17 Kerkhofs M, Van Cauter E, Van Onderbergen A, Caufriez A, Thorner MO \& Copinschi G. Sleep-promoting effects of growth hormone-releasing hormone in normal men. American Journal of Physiology 1993264 E594-E598.

18 Rechtschaffen A \& Kales A. A Manual of Standardized Terminology. Techniques and Scoring Systems for Sleep Stages of Human Subjects. Los Angeles: UCLA Brain Information Service/Brain Research Institute, 1968.

19 Jaffe CA, DeMott-Friberg R \& Barkan AL. Suppression of growth hormone $(\mathrm{GH})$ secretion by a selective GH-releasing hormone
(GHRH) antagonist. Journal of Clinical Investigation 199392 695-701.

20 Obal F Jr, Alt J, Taishi P, Gardi J \& Krueger JM. Sleep in mice with nonfunctional growth hormone-releasing hormone receptors. American Journal of Physiology - Regulatory Integrative Comparative Physiology 2003 284 R131-R139.

21 Garry P, Roussel B, Cohen R, Biot-Laporte S, Charfi AE, Jouvet M \& Sassolas G. Diurnal administration of human growth hormonereleasing factor does not modify sleep and sleep-related growth hormone secretion in normal young men. Acta Endocrinology $1985110158-163$.

22 Kupfer DJ, Jarret DB \& Ehlers CL. The effect of GRF on the EEG sleep of normal males. Sleep $1991 \mathbf{1 4} 87-88$.

23 Kern W, Halder R, al-Reda S, Spath-Schwalbe E, Fehm HL \& Born J. Systemic growth hormone does not affect human sleep. Journal of Clinical Endocrinology and Metabolism $1993 \mathbf{7 6}$ $1428-1432$.

24 Jaffe CA, DeMott-Friberg R \& Barkan AL. Endogenous growth hormone $(\mathrm{GH})$-releasing hormone is required for $\mathrm{GH}$ responses to pharmacological stimuli. Journal of Clinical Investigation 1996 97 934-940.

25 Russell-Aulet M, Jaffe CA, Demott-Friberg R \& Barkan AL. In vivo semiquantification of hypothalamic growth hormone-releasing hormone $(\mathrm{GHRH})$ output in humans: evidence for relative GHRH deficiency in aging. Journal of Clinical Endocrinology and Metabolism 199984 3490-3497.

26 Orrego JJ, Russel-Aulet M, Demott-Friberg R \& Barkan AL. Semiquantification of hypothalamic GH-releasing hormone output in women: evidence for sexual dimorphism in the mechanism of the somatopause. Journal of Clinical Endocrinology and Metabolism $2001865485-5490$.

27 Lumpkin MD \& McDonald JK. Blockade of growth hormonereleasing factor (GRF) activity in the pituitary and hypothalamus of the conscious rat with a peptidic GRF antagonist. Endocrinology $19891241522-1531$.

28 Marshall L, Derad I, Strasburger CJ, Fehm HL \& Born J. A determinant factor in the efficacy of GRH administration in promoting sleep: high peak concentration versus recurrent increasing slopes. Psychoneuroendocrinology 199924 363-370.

29 Maheshwari HG, Silverman BL, Dupuis J \& Baumann G. Phenotype and genetic analysis of a syndrome caused by an inactivating mutation in the growth hormone-releasing hormone receptor: Dwarfism of Sindh. Journal of Clinical Endocrinology and Metabolism $1998834065-4074$.

30 Roelfsema F, Biermasz NR, Veldman RG, Veldhuis JD, Frolich M, Stokvis-Brantsma WH \& Wit JM. Growth hormone (GH) secretion in patients with an inactivating defect of the GH-releasing hormone $(\mathrm{GHRH})$ receptor is pulsatile: evidence for a role for non-GHRH inputs into the generation of GH pulses. Journal of Clinical Endocrinology and Metabolism 2001 86 2459-2464.

Received 21 April 2004

Accepted 19 August 2004 